\title{
Undergraduate Students' Pro-Environmental Behavior in Daily Practice
}

\author{
Widiaswati Dewi ${ }^{1, *}$, Sawitri Dian $\mathrm{R}^{2}$ \\ ${ }^{1}$ Master Program of Environmental Science, School of Postgraduate Studies, Diponegoro University, Semarang - Indonesia \\ ${ }^{2}$ Faculty of Psychology, Diponegoro University, Semarang - Indonesia
}

\begin{abstract}
Pro-environmental behavior is an individual action as a manifestation of one's responsibility to create a sustainable environment. University students as one of the agent of change can adopt proenvironmental behaviors concept, even through simple things to do on daily activities such as ride a bicycle or walk for short distance, reuse the shopping bags, separate waste, learn about environmental issues etc. Many studies have examined pro-environmental behavior from various approaches. However, the study about university students' pro-environmental behavior is lacking. The aim of this paper is to examine the undergraduate students' pro-environmental behaviors level. We surveyed 364 first year undergraduate students from a state university in Semarang. The survey included six aspects of proenvironmental behavior in daily practice which include energy conservation, mobility and transportation, waste avoidance, recycling, consumerism, and vicarious behaviors toward conservation. Findings of this study showed the level of pro-environmental behavior of first year undergraduate students is medium. Recommendations for undergraduate students and future researchers are discussed.
\end{abstract}

\section{Introduction}

Pro-environmental behavior (PEB) is an individual action as a manifestation of one's responsibility to create a sustainable environment. It will be based on the presence of a wide range of environmental problems that threaten environmental sustainability [1] for example, IPCC reported that climate change had affected the nature and human life [2].

Therefore to ensure environmental sustainability, young people need to be led to behave which environmental friendly [3], because those will be exposed to the effects of environmental problems in the future [4]. In addition, young people are critical stakeholders [5], including in it is the university students.

The university students can adopt pro-environmental behavior in everyday life, e.g., recycling, carpooling or driving hybrid vehicles, using energy-efficient appliances, making ecologically conscious purchases [6]. In previous studies, pro-environmental behavior at an individual level are influenced by demographic factors [7], whereas in general literature makes it clear that PEB are influenced by social-psychological and socialdemographic factors [3].

First year for the university (undergraduate) students is an important phase to adapt to life at the university, where the literature consistently mentions that first year was an important stage in shaping student attitudes and affects the persistence [8]. In this situation, proenvironmental behaviour adopting the process is very possible through the influence at the university current conditions.

The study about pro-environmental behavior has increased along with the popularity of sustainable concepts on academics, practitioners, government etc.. However, the study about freshmen' pro-environmental behavior is lacking, even though it is one of the important points to predict the students' potential. The aim of this paper is to examine freshmen' proenvironmental behaviors level.

\section{Method}

\subsection{Participants}

Participants were 364 first year undergraduate students (freshmen) from a state university in Semarang, which include two major programs (social \& humanity and science \& technology). The participants' profiles are shown in Table 1.

\subsection{Survey materials}

All responses were made using a 5-point Likert-like scale $(1=$ never, $2=$ seldom, $3=$ occasionally, $4=$ often, $5=$ always $)$.

The 36-item Pro-Environmental Behavior Scale was modified from General Ecological Behavior Scale [9]. It measures adolescent six aspects of pro-environmental

Corresponding author: dewiwidiaswati@gmail.com 
behavior in daily practice which include energy conservation, mobility and transportation, waste avoidance, recycling, consumerism, and vicarious behaviors toward conservation. A sample item, "I ride a bicycle, take public transportation or walk to campus". Cronbach's alpha of this 36-item scale has been reported as .669.

Table 1. Profile of survey participants $(n=364)$

\begin{tabular}{|l|l|l|}
\hline & Frequency & Percentage \\
\hline Major & & \\
\hline Social \& Humanity & 119 & 32.7 \\
\hline $\begin{array}{l}\text { Science \& } \\
\text { Technology }\end{array}$ & 245 & 67.3 \\
\hline Gender & & \\
\hline Female & 231 & 63.5 \\
\hline Male & 133 & 36.5 \\
\hline
\end{tabular}

\subsection{Data collection procedure}

Research assistants administered the questionnaires to students in classroom. Participation in this study was completely voluntary. Ethics approval was obtained.

\section{Results and discussion}

\subsection{Freshmen' pro-Environmental behavior in daily practice}

Participants indicated that their pro-environmental behavior higher while outside the campus, except for waste avoidance (see Fig. 1). It is influenced by the type of activity and several infrastructures which is around an individual location when carrying out the activities.

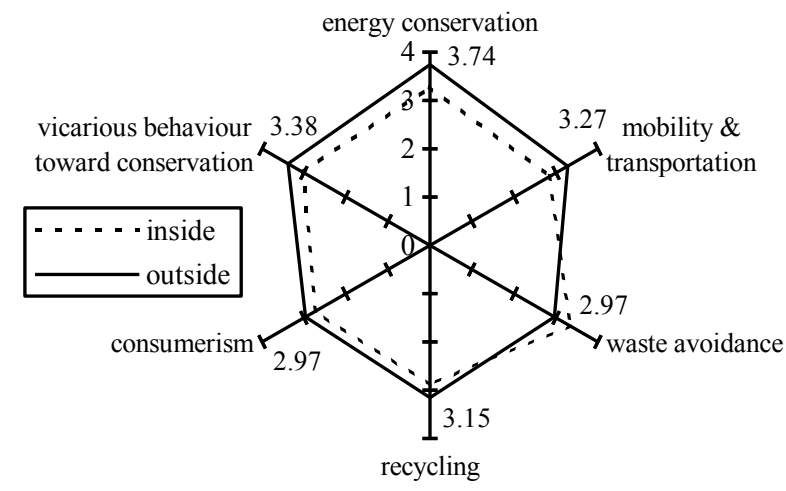

Fig. 1. Freshmen' Pro-environmental behavior in daily practices (inside \& outside campus)

In general, the students show that they are most concerns with energy conservation. It was similar with case in Ohio Wesleyan University (OWU) which in general the students are concerned with energy conservation and recycling than another aspect of proenvironmental behavior [10]. This condition is a little different from Lithuanian students. The Lithunanian students are most concerns in recycling, while the other aspect of pro-environmental behavior such as saving energy or water and using more sustainable transportation are lacked of interest [11]. The difference is shown that demographic factors play an important role to shape pro-environmental behavior, because proenvironmental behavior itself is a function of the attitude/environmental ethics and various social demographic factors [12]. In addition, pro-environmental behavior has other antecedent variables that influence in a complex way (see Table 2).

Table 2. Antecedents of university students' proenvironmental behavior

\begin{tabular}{|l|l|}
\hline Antecedent & Main Source \\
\hline Demographics & {$[15],[10]$} \\
\hline Education & {$[10],[16]$} \\
\hline Environmental beliefs & {$[17]$} \\
\hline Gender & {$[4]$} \\
\hline Major /academic backgrounds & {$[14],[17]$} \\
\hline Motivation & {$[4]$} \\
\hline Self-efficacy & {$[15]$} \\
\hline Value orientations & {$[11]$} \\
\hline
\end{tabular}

Pro-environmental behavior basically aims to reduce environmental problems [13]. In daily practice, an individual face some barriers to engage in PEB, these barriers include personal cost, inconvenience, and lack of time to conduct conservation [14]. Thus, to engage in pro-environmental behavior the students can do various behavior that suitable for their conditions. It is very important because the students as one of the agent of change will become a professional, as exemplars for the general public to emulate [14].

\subsection{Six aspects of pro-environmental behavior}

Table 3 presented that freshmen' pro-environmental behavior in general are at medium category. These result are influenced by the condition in which first year at the university is undergoing a phase of transition from highschool students to university students. A wide range of dispositions, conceptions, motivational tendencies and prior knowledge color the way an individual students sees their new learning environment [8], so that the behavior demonstrated by everyone is the response of the overall condition.

The increase of age and year at university will be effected on pro-environmental behavior, even though it does not have a constant effect [10]. This is in line are assumed by Vicente-Molina that people with more education are more likely to develop environmental performance [4], but keep in mind that proenvironmental behaviors are shaped by complex combination factors [14].

Pro-environmental behavior of everyone has various forms, among which are:

a. Energy conservation. Related activities include to save energy or purchase energy captured in a cleaner way.

b. Mobility and transportation. Related efforts to reduce carbon emissions through the choice in the 
type of environment-friendly transport (e.g., using public transport, ride bikes or walk to reach a minimum distance).

c. Waste avoidance. Related things that aim to avoid or manage waste that arises (e.g., minimize the use of plastic, buy refill product).

d. Recycling. Related activities that aim to recycle the materials used been unused.

e. Consumerism. Related on the use or consumption of eco-friendly product like organic products.

f. Vicarious behaviors toward conservation. Related activities that generally do not give a negative effect to the environment.

Table 3. Distribution of Freshmen' Pro-environmental behavior

\begin{tabular}{|l|l|l|}
\hline Aspects & Description & Percentage \\
\hline \multirow{3}{*}{$\begin{array}{l}\text { energy } \\
\text { conservation }\end{array}$} & low & 2.2 \\
\cline { 2 - 3 } & medium & 74.2 \\
\cline { 2 - 3 } & high & 23.6 \\
\hline \multirow{2}{*}{$\begin{array}{l}\text { mobility and } \\
\text { transportation }\end{array}$} & low & 11.0 \\
\cline { 2 - 3 } & medium & 77.2 \\
\cline { 2 - 3 } waste & high & 11.8 \\
\hline \multirow{4}{*}{ avoidance } & low & 4.7 \\
\cline { 2 - 3 } & medium & 87.2 \\
\cline { 2 - 3 } recycling & high & 8.2 \\
\hline \multirow{4}{*}{$\begin{array}{l}\text { consumerism } \\
\text { low }\end{array}$} & medium & 6.9 \\
\cline { 2 - 3 } & high & 89.3 \\
\cline { 2 - 3 } & low & 3.8 \\
\cline { 2 - 3 } $\begin{array}{l}\text { vicarious } \\
\text { behavior } \\
\text { toward } \\
\text { conservation }\end{array}$ & high & 6 \\
\cline { 2 - 3 } & low & 92.9 \\
\cline { 2 - 3 } & medium & 1.1 \\
\hline
\end{tabular}

As it has been mentioned before that the participant has the greatest attention on energy conservation. It becomes a point that Indonesia does have an intensive promotion of energy conservation. It's seen through the rank of Indonesia Environmental Performance Index (EPI) which at position 41 for indicator energy and climate in 2016 [18].

Based on the results of measurements on samples retrieved that students have a diverse response magnitude on each aspect of the pro-environmental behavior, so it can be said that each student has a different 'sustainability lifestyles'. The students' sustainability lifestyles is significant to be improved, because it can play a role in the process of promoting desirable behavioral changes. It is becoming increasingly attractive given that university students as one of the agents of change in the future have a significant role, and if future talent can take decisions that are beneficial to the environment, society is more likely to make progress along the path towards sustainability [4].

However, the limitation of the current study must be noted before these results are generalized. Perhaps the main limitation of the current study is the proportion of the sample is based on the total number on each faculty/ major program (not specific in distribution of all undergraduate programs).

\section{Conclusions}

The aim of this study was to examine the undergraduate students' pro environmental behaviors level. It was discovered that freshmen' pro-environmental behaviors levels in general are medium. Therefore, necessary efforts to improve undergraduate students' proenvironmental behavior, because they are the leaders on the future, and thus capable of making a difference in the next decades [19]. In terms that university as a second home to the students has an important role for creating sustainable environment, examples through stir institutional changes over and above interventions aimed at changing individual behavior [20].

\section{Acknowledgments}

We would like to thank all the participants and the research assistants for their willingness and time to participate in this study.

\section{References}

1. L. Steg, C. Vlek, Journal of Environmental Psychology 29, 309 (2009)

2. E. Margetts, Y. Kashima, Journal of Environmental Psychology 49, 30 (2017)

3. D. Hooi, C. Fang, C. Cheng. Journal of Hospitality, Leisure, Sport \& Tourism Education 20, 16 (2017)

4. M. A. Vicente-molina, A. Fernández-sáinz, J. Izagirre-olaizola, Journal of Cleaner Production 61, 130 (2013)

5. A. Leeuw, P. Valois, I. Ajzen, P. Schmidt, Journal of Environmental Psychology 42, 128 (2015)

6. A. Hergatt, B. R. Werff, J. B. Henning, K. Watrous-rodriguez, Journal of Environmental Psychology 38, 262 (2010)

7. X. Yu, Journal of Environmental Psychology 38, 39 (2014)

8. E. E. Ketonen, A. Haarala-muhonen, L. Hirsto, J. J. Hänninen, K. Wähälä, K. Lonka, Learning and Individual Differences 51, 141 (2016)

9. F. G. Kaiser, B. Oerke, F. X. Bogner, Journal of Environmental Psychology 27, 242 (2007)

10. A. Meyer, Journal of Cleaner Production 112, 3451 (2016)

11. M. S. Poskus, Curr Psychol, (2016)

12. G. D. Lee, D. Hong, J. Liu, Environmental Conservation 38, 45 (2011)

13. A. Homburg, A. Stolberg, Journal of Environmental Psychology 26, 1 (2006)

14. J. Easton, M. Koro-ljungberg, J. C. Cheng, Applied Environmental Education and Communication 8, $126(2009)$ 
15. S. Kim, S. Jeong, Y. Hwang, Science Communication 35, 2 (2012)

16. S. Ajaps, R. Mclellan, Cogent Education 28, 1 (2015)

17. M. Cordano, S. Welcomer, R. Scherer, L. Pradenas, V. Parada, The Journal of Environmental Education 41, 4 (2010)
18. A. Hsu, 2016 Environmental Performance Index, New Haven (2016)

19. M. Yazdanpanah, M. Forouzani, Journal of Cleaner Production 107, 342 (2015)

20. P. Mtutu, G. Thondhlana, Habitat International 53, 142 (2016) 